\title{
Climate change and health: a challenge for epidemiology and public health
}

\author{
Francesco Forastiere
}

Published online: 2 December 2009

(c) Birkhäuser Verlag, Basel/Switzerland 2009

This special issue of the Journal will be coming out when the countdown to the Copenhagen Conference on Climate Change (CC) in December 2009 will have ended and world policy makers will be deciding about our future and of those of the coming generations. The activity of the World Health Organization (WHO), international and national institutions, NGOs, and different sectors of society has been high in the last months to inform, raise awareness, create solidarity, increase media coverage, bring policy makers up to date on a large portion of the "inconvenient truth": CC is the biggest global health threat of the twentyfirst century. To get an instant idea, just google "climate change and health" on the web. We will see the effectiveness of all these efforts in the post-Copenhagen period. Certainly, epidemiologists and public health professionals will be presented with important future challenges but there will be many opportunities to shift from the comforts of prevailing ideas and intellectual habits to a different approach in research and in prevention. Many of the papers in this issue see the challenges and anticipate the opportunities. Let us mention some of them.

As McMichael (2008) has already indicated, the dynamics of factors leading to climate changes and to health effects is extremely complex, involving environmental, ecological and social aspects. Strong economical interests together with individual and community behaviors

This paper belongs to the special issue "Climate changes health".

F. Forastiere $(\varangle)$

Department of Epidemiology, Regional Health Service, Lazio,

Via Santa Costanza, 53, 00198 Rome, Italy

e-mail: forastiere@asplazio.it are also powerful driving forces. All these factors have large, entangled interactions. The challenge for epidemiology is to apply new modes of approaching and studying the issue, while continuously searching for collaboration from other disciplines. Several aspects of the roadmap are well summarized in the comprehensive essay by CampbellLendrum et al. (2009) and by Vineis (2010). First, there is a need for appropriate methods to conceptualize the full chain of events leading to potential health effects. Here, the new principles of integrated environmental impact assessment of systemic risks (Briggs 2008) should be taken with interest as a way to overcome the limitations of traditional risk assessment. Second, there is a continuous need to consider the scale of the epidemiological evaluation. It is not only a matter of applying hierarchical modeling to multivariate analysis (Victora et al. 1997), but also a way should be found to integrate our learning of the risk factors at both the population and the individual level, to give more weight to comparisons between populations without losing the interest to micro level analysis; "forests" should be scrutinized without missing our interest in "trees" (Pearce 1996). Third, the socio-economical conditions and contexts should always be kept in mind, at both the population and individual level, as they have profound health consequences. Poverty makes people more vulnerable to the effect of CC and its greatest impact has been predicted in populations with few resources (Jay and Marmot 2009). Finally, the inventory of potential health effects of CC should be enlarged. We do not yet have a clear idea of the long-term impact on a population's mental health of "natural" disasters like hurricane Katrina or of the current economic crisis and insecurity (Somasundaram and van de Put 2006). Still, psychological effects of climate change have been well postulated in Kjellstrom's (2010) paper and they deserve attention and evaluation. 
The impacts of $\mathrm{CC}$ on health are difficult to predict as we are speaking of the future and there are many uncertainties in the predictions, making people sceptical and unwilling to see potential consequences of the present unsustainable, aggressive energy-consuming attitude of our societies. The challenge is to enlarge the empirical databases, conduct studies on the effect of climate variability today, increase the ability to predict and diminish the number of uncertainties (Sunyer and Grimalt 2006). This is where epidemiology should play a major role in providing new information. But an additional duty is to address uncertainties. Too often, we believe that our confidence intervals are the most accurate representation of the degree of our uncertainty. False, of course, as several key factors and parameters may be missing and the confidence intervals represent only the statistical portion of the overall uncertainty. Several methods to deal with these aspects (Knol et al. 2009) have been proposed. To make it simple, however, we should recognize that from the IPCC (2005) document we have learnt how to systematically state, for each step in an evaluation, a level of confidence based on expert judgment to characterize uncertainty in terms of the correctness of data, model, analysis or statement-a simple scale that could be used in many contexts.

Over several years, there has been controversy about whether the mission of epidemiology should entail the duty to "eradicate poverty" (Rothman et al. 1998); certainly today, the $\mathrm{CC}$ is becoming an ethical duty for health professionals. Physicians and professionals involved in public health, including epidemiologists, could play an important role in active support of change in communities and individual policies and behaviors, advocacy is the term for some, primary prevention for others. The European Respiratory Society provided a recent statement on the issue (Ayres et al. 2009), as a good example of advocacy activity. It is obvious that immediate governmental action is required to change the future of the planet, but action by healthcare professionals at an individual level may bring about significant incremental effects. As a trusted source, physicians can disseminate information and set an example to their patients, families, communities, and organisations by taking steps to reduce the carbon footprint of their homes and practices. Public health professionals have the power to indicate that we all need to take responsibility in order to reduce overall energy consumption by increasing energy efficiency, reducing automobile dependence, promoting physical activity, contrasting obesity (Edwards and Roberts 2009), reducing meat consumption (Powles 2009), promoting use of local food and, finally, considering what we do and eat as an integral part of policy on climate change.

\section{References}

Ayres JG, Forsberg B, Annesi-Maesano I, Dey R, Ebi KL, Helms PJ, Medina-Ramón M, Windt M, Forastiere F (2009) Environment and Health Committee of the European Respiratory Society. Climate change and respiratory disease: European Respiratory Society position statement. Eur Respir J 34(2):295-302

Campbell-Lendrum D, Bertollini R, Neira M, Ebi K, McMichael A (2009) Health and climate change: a roadmap for applied research. Lancet 373(9676):1663-1665

Edwards P, Roberts I (2009) Population adiposity and climate change. Int J Epidemiol 38:1137-1140

Intergovernmental Panel on Climate Change (2005) Guidance notes for lead authors on the IPCC fourth assessment report on addressing uncertainty. http://ipcc-wg1.ucar.edu/wg1/Report/ AR4_UncertaintyGuidanceNote.pdf

Jay M, Marmot MG (2009) Health and climate change. Lancet 374(9694):961-962

Kjellstrom T (2010) Public health impact of global heating due to climate change - potential effects on chronic non-communicable diseases. Int J Public Health. doi:10.1007/s00038-009-0090-2

Knol AB, Petersen AC, van der Sluijs JP, Lebret E (2009) Dealing with uncertainties in environmental burden of disease assessment. Environ Health 8:21

McMichael AJ (2008) Environmental change, climate and population health: a challenge for inter disciplinary research. Environ Health Prev Med 13(4):183-186

Pearce N (1996) Traditional epidemiology, modern epidemiology, and public health. Am J Public Health 86(5):678-683

Powles J (2009) Commentary: why diets need to change to avert harm from global warming. Int J Epidemiol 38:1141-1142

Rothman KJ, Adami HO, Trichopoulos D (1998) Should the mission of epidemiology include the eradication of poverty? Lancet 352(9130):810-813

Somasundaram DJ, van de Put WA (2006) Management of trauma in special populations after a disaster. J Clin Psychiatry 67(Suppl 2):64-73

Sunyer J, Grimalt J (2006) Global climate change, widening health inequalities, and epidemiology. Int J Epidemiol 35(2):213-216

Victora CG, Huttly SR, Fuchs SC, Olinto MT (1997) The role of conceptual frameworks in epidemiological analysis: a hierarchical approach. Int J Epidemiol 26(1):224-227

Vineis P (2010) Climate change and the diversity of its health effects. Int J Public Health. doi:10.1007/s00038-009-0092-0 